УДК 304

$10.17213 / 2075-2067-2021-3-270-280$

\title{
КУЛЬТУРНЫЙ ИММУНИТЕТ РОССИЙСКОГО ОБЩЕСТВА В НАУЧНОМ ДИСКУРСЕ
}

\author{
(C) 2021 г. . А. Пономарев , И. А. Тищенко ${ }^{* *}$ И. С. Якунина
}
"Донской государственный технический университет, г. Ростов-на-Дону, Россия
"Ш Шахтинский автодорожнный институт (филиал), Южнно-Российский государственный политехнический университет (НПИ) имени М. И. Платова, г. Шахты, Россия

Предметом данной статьи выступает научный дискурс, сложившийся в пространстве современного социально-гуманитарного знания относительно такой актуальной, но еще недостаточно исследованной проблемы, как культурный иммунитет российского общества. Подобный анализ крайне важен в условиях роста деструктивных явлений, разрушающих культуру и культурный иммунитет российского общества вследствие иелой серии постсоветских реформ и влияния культурной глобализачии.

Автор характеризует пространство сложивиихся дискурсивных практик в отношении культурного иммунитета как пространство практик дисциплинарных, а потому методологически ограниченных и не позволяющих сформировать иелостное представление и знание о таком социальном явлении, как культурный иммунитет общества.

Методологическую основу исследования составляет органическая теория, в рамках которой зародилась теория социального иммунитета, а также положения неоинституционального и системного подходов. В их рамках культурньй иммунитет предстает как элемент иммунной системы общества, выполняющий защитные функции и обеспечивающзий механизм устойчивого культурного воспроизводства и самосохранения общества как социиокультурной целостности.

Результаты и перспективы исследования. По итогам исследования делается вывод о том, что на уровне сочииально-философской рефлексии феномен культурного иммунитета практически не исследован, притом именно в методологических границах этой отрасли научного знания есть возможность получения целостного знания об изучаемом явлении. Такую возможность предоставляет трансдисциплинарная парадигма, применение которой, с точки зрения авторов статьи, наиболее перспективно в концептуализаичии и последующем социально-философском изучении культурного иммунитета российского общества.

Ключевые слова: культурный иммунитет; культура; глобализация; культурная глобализация; иммунная система; трансдисииплинарная парадигма. 


\title{
CULTURAL IMMUNITY OF THE RUSSIAN SOCIETY IN THE SCIENTIFIC DISCOURSE
}

\author{
(C) 2021 P. A. Ponomarev*, I. A. Tishchenko**, I. S. Yakunina ${ }^{* *}$ \\ "Don State Technical University, Rostov-on-Don, Russia \\ ${ }^{*}$ Shakhty Road Institute (branch), \\ Platov South Russian State Polytechnic University (NPI), Shakhty, Russia
}

The subject of this article is the scientific discourse that has developed in the space of modern social and humanitarian knowledge regarding such an urgent, but still insufficiently studied problem as the cultural immunity of Russian society. Such an analysis is extremely important in the context of the growth of destructive phenomena that destroy the culture and cultural immunity of Russian society due to a series of post-Soviet reforms and the influence of cultural globalization.

The author characterizes the space of established discursive practices in relation to cultural immunity as a space of disciplinary practices, which are therefore methodologically limited and do not allow forming a holistic view and knowledge of such a social phenomenon as cultural immunity of society.

The methodological basis of the research is the organic theory as the one in which the theory of social immunity was born, as well as the provisions of the neoinstitutional and systemic approaches. In their framework, cultural immunity appears as an element of the immune system of society, performing protective functions and providing a mechanism for sustainable cultural reproduction and self-preservation of society as a socio-cultural integrity.

Results and prospects of the study. The study concluded that the level of social-philosophical reflection of the phenomenon of cultural immunity are virtually unexplored despite the fact that in the methodologicalboundaries of this branch of scientificknowledgeit is possible to obtain holisticknowledge about the studied phenomenon. This opportunity is provided by the transdisciplinary paradigm, the application of which, from the authors' point of view, is most promising in the conceptualization and subsequent socio-philosophical study of the cultural immunity of Russian society.

Key words: cultural immunity; culture; globalization; cultural globalization; immune system; transdisciplinary paradigm.

Введение. Культура как социальный феномен детерминирует коллективный характер и способ жизнедеятельности социума [31], а также любые перемены и инновации, которые в силу социальной обусловленности культуры и взаимосвязанности всех социальных сфер в прямом или косвенном виде являются следствием изменений в культурной сфере [30].

Но далеко не все инновации приживаются в обществе и далеко не все из них имеют позитивный характер по своим последствиям. Какие-то новации, реформы принимаются в обществе, внедряются в социальные практики, приносят свой положительный результат. Другие же отторгаются, вызывают резкое неприя- тие у населения, актуализируя те адаптационные практики и механизмы, которые в большей степени соответствуют социокультурной природе общества. Почему так происходит? Почему не все инновации воспринимаются социальным организмом? Почему по-разному на жизнедеятельности различных обществ сказываются одни и те же, порой очень прогрессивные и, казалось бы, крайне важные для общества реформы?

Методология исследования. На эти вопросы ученые отвечают по-разному в свете различных методологических подходов, концепций. Из них широкую известность полу- 
чили те, что обращаются к социокультурной, исторической, цивилизационной самобытности общества, имеющей свою логику социогенеза и институционального развития, которая и порождает феномен зависимости настоящего от прошлого, определяющий возможности каждого общества к переходу в иной формат социокультурного развития с учетом внедрения актуальных для современной реальности реформ и инноваций. Здесь можно вспомнить и теорию исторической колеи [14], и неониституциональный подход [25], и теорию архаизации [3], и концепцию социальной инерции [13]. Все они, по сути, акцентируют внимание на идее институциональной преемственности и зависимости в социокультурной динамике общества, и не согласиться с этой идеей невозможно, поскольку на протяжении всей российской истории с каждым витком реформ и преобразований наблюдается этот эффект зависимости. Большинство российских реформ еще с петровских времен сводились к одному алгоритму — импорту моделей развития западного общества, причем без учета собственной специфики, социокультурного своеобразия российской цивилизации, ее ресурсного потенциала и механизмов развития [1]. И так происходит до сих пор. Российская традиция как культурная субстанция пыталась их перекроить под себя. Получалось это не всегда, но опасность заключается в том, что такие попытки каждый раз оборачивались разрушением самой Традиции, которая выступает основой культурного иммунитета общества как его способности противостоять рискам и угрозам как внешнего, так и внутреннего характера с целью самосохранения и способности к культурному воспроизводству.

В связи со сказанным выше полагаем, что тематика, связанная с изучением культурного иммунитета общества, является сверхактуальной для современного российского общества, уже более двадцати пяти лет находящегося в состоянии реформ и турбулентности и все ищущего свой путь развития. А тем временем снижается культурный иммунитет общества, что проявляется в самых различных негативных явлениях и процессах, начиная от засилья «мусорной» культуры [4], падения культурного уровня и духовности населения, снижения грамотности и воспитанности, и заканчивая полным разрушением культу- ры общения, особенно межэтнического [24], между представителями различных народов, населяющих нашу страну.

В данной статье мы хотим проанализировать сложившийся в научном пространстве дискурс относительно такого явления, как культурный иммунитет общества, с тем, чтобы обосновать потребность и необходимость в его социально-философской концептуализации с учетом накопленного опыта в различных дисциплинарных практиках и дефицита собственно социально-философских концептуальных разработок.

Результаты исследования. Следует сразу обратить внимание на то, что тематика, связанная с иммунитетом общества, в социальной и философской мысли зависит от органического направления. Именно в рамках органицизма иммунная система общества могла получить свое теоретическое обоснование, поскольку, как известно, само понятие иммунитета социальными науками было заимствовано из биологической науки и медицинской практики. Иммунной терминологией пользовались и Ф. Ницше, и Ж. Деррида, и Н. Луман, но, как отмечают представители естественнонаучного направления, «в социальных исследованиях происходит так называемая денатурализация (когда какой-либо объект лишают статуса природного, объективно существующего) и деконтекстуализация (вывод объекта из привычного контекста, например, научных лабораторий и книг). В первом случае речь идет о том, что иммунные системы не могут однозначно считаться натуральными (природными) объектами и их появление зависит от деятельности ученых и настройки оборудования. Деконтекстуализация (отрыв от контекста) приводит к вариативности в объяснениях. Одни и те же визуальные данные могут быть по-разному истолкованы, что в итоге приведет к построению разных моделей иммунных систем и иммунологических теорий» [29].

По сути, так и произошло. Сегодня учеными сконструированы различные модели и теории, в которых фигурирует понятие иммунитета, иммунной системы общества, но до сих пор популярностью пользуется направление, заложенное представителями органического направления в социально-философской мысли. 
В российской социально-философской мысли это направление связано с именем П. Лилиенфельда, в 1868 году изложившего свои идеи и взгляды в работе «Земля и воля», в которой он, отталкиваясь от положений органической теории, показал связь между развитием общества и его духовным уровнем, потенциалом с акцентом на ключевой роли образования в формировании культурного образа народа [17].

Общество как организм, подобный биологическому, - вот ключевая идея организмического мировоззрения, получившего распространение еще в XVIII в. в трудах И. Канта и Ф. Шеллинга, социологов-позитивистов (Г. Спенсера, А. Шеффле), а также российского социолога философа П. Лилиенфельда, для которого общество выступало в виде органической системы, состоящей из нервных клеток, интегрированных в такие подсистемы, как семья, род, племя, народ, раса, в совокупности названные этим ученым живой тканью общества [18].

По аналогии с биологическим организмом общество на протяжении своего развития вырабатывает собственный иммунитет, в социологической науке названный социальным. Этот иммунитет позволяет обществу защищаться от чужеродных влияний, блокировать их негативное воздействие, тем самым сохраняя адаптивный потенциал и стабильность в развитии [5]. В рамках теории социального иммунитета различного рода разрушительные и дисфункциональные явления и процессы в общественном организме рассматриваются как нарушения в иммунной системе общества. И неудивительно, что теория социального иммунитета получила свое глубокое изучение именно в российской социологической науке в свете последних десятилетий, ознаменовавшихся кризисными явлениями в самых различных сферах общественной жизни на фоне тенденций деконсолидации [33], роста конфликтогенности в сфере межэтнических, конфессиональных, межпоколенческих и иных отношений [27], острого дефицита социального доверия и духовного упадка [6], снижения социального самочувствия, здоровья, особенно в молодежной среде [28].

Об этом говорят также данные всероссийских опросов и аналитических разработок, а сами социологи отреагировали разработкой целостной концепции социального иммунитета $[11,12]$, обращением к российским реалиям, к социальным группам и проблемам их жизнедеятельности, становления социальной субъектности, жизненной самореализации с теоретических позиций данной концепции [32]. Теория социального иммунитета применяется также в других отраслях социально-гуманитарного знания в контексте осмысления жизнедеятельности отдельных социальных групп, их адаптации к современной реальности. Так, А.В. Морозов обратился к проблеме формирования социального иммунитета у подростков с позиций педагогической науки, понимания социального иммунитета как «способности человека противостоять изменению его нормальной социализации под воздействием внешних деформаций» [23].

Интерес социальной философии к проблеме иммунитета общества неминуемо связан с темой культуры, поскольку сам механизм социокультурного развития общества через погружение в мир культуры, в саму культуру как первопричину социальных изменений ставит самым злободневным образом вопрос о культурном иммунитете общества. Любые новации, внедряемые в социальную ткань общества, проходят так называемый «культурный фильтр», проверку на соответствие социокультурным устоям, традициям, основаниям данного общества. Об этом пишет С. Кара-Мурза в контексте проблемы кризиса культуры, который, согласно его мнению, возникает, когда в культуру «внедряется крупная идея, находящаяся в непримиримом противоречии с другими устоями данной культуры - люди теряют ориентиры, путаются в представлениях о добре и зле» [15]. Культура в такой ипостаси в координатах органической теории выступает в роли «средства физической, интеллектуальной и психологической защиты человека и сообщества от внешних угроз» [19].

Таким образом, вполне закономерен и актуален вопрос о культурном иммунитете как защитном механизме в социокультурной динамике общества, но, как ни парадоксально, в социальной философии тематика культурного иммунитета еще ждет своего глубокого изучения, представляя перспективное направление исследования. В.А. Куц, один 
из немногих, обратившихся к категории культурного иммунитета на уровне философско-культурологической рефлексии, видит особенность культурного иммунитета в том, что он не подконтролен сознанию, поскольку функционирует на подсознательном уровне как «система саморегуляции информационных систем, система защиты в культуре, которая должна защищать наш собственный интеллект и культуру общества от дестабилизирующих влияний иных культур», но данная защита функционирует на основе саморегуляции, является незаметной [20].

Режим саморегуляции культуры может иметь и отрицательный характер, когда запущены механизмы разрушения культуры, о чем пишет С. Кара-Мурза, обращаясь к истокам причин, создавших на современный момент ситуацию национальной катастрофы в результате сокрушительного удара по культуре постсоветских реформ [15]. Разрушительные процессы в российской культуре вошли в режим самовоспроизводства, что и определяет, по мнению С. Кара-Мурзы, масштаб национальной катастрофы, особенно с учетом того, что ни на уровне государства, ни на уровне общества не выработаны механизмы противостояния этим процессам, что говорит о критическом состоянии культурного иммунитета общества.

Если культурный иммунитет определяет уровень защищенности всей социокультурной системы общества, ее способность к самовопроизводству, то основой иммунитета самой культуры выступают ее глубинные основания, которые подобно иммунитету, обеспечивающему генетическую целостность организма, призваны сохранить культуру, независимо от влияния различных факторов внешнего и внутреннего свойства [22].

В научном дискурсе относительно культуры и ее защищенности в условиях современной российской реальности поднимается также вопрос о доминантных факторах, определяющих состояние и динамику культуры в России. Многие ученые видят во внешних влияниях источник динамичных изменений в российской культуре, связывая их с глобализацией и ее ценностями [16], с культурной глобализацией как таковой [26], с цифровизацией и информатизацией современного мира, с негативным влиянием СМИ, Интернета, продук- цию которого молодежь впитывает, не имея культурного иммунитета для того, чтобы избирательно подходить к потоку информации в современном информационном пространстве [2]. С этими процессами связывают проблему роста бездуховности, агрессивности и в целом культурной деградации в современном российском обществе. Однако следует заметить, что дегуманизация культурной сферы - проблема не только российского масштаба. Она характерна для всего современного мира, и ученые разных стран пишут о вызовах и угрозах XXI века, производных от деградации духовности современного мирового сообщества и выливающихся в волнах агрессии, насилия, терроризма и др. $[7,8]$.

Признавая закономерность культурной глобализации, исследователи в качестве серьезной угрозы указывают на тенденцию упрощения культурных практик в рамках массовизации культуры, в то время как прогресс в любой сфере, в том числе и в культурной, ассоциируется с усложнением социальной системы, расширением степеней ее свободы. Можно вновь обратиться к авторитетному мнению российского ученого о том, что «усложнение культуры как самодостаточной системы является универсальным признаком ее прогрессивного развития», но по данному критерию, как полагает сам автор этих слов А. Я. Флиер, «современное состояние отечественной культуры никак не несет в себе черт прогрессивного развития» [30].

Высокая степень встроенности современного культурного процесса в систему социально-экономических отношений, в экономическую систему не только упрощает культурный процесс, но и способствует сегрегации культуры на «шоу-бизнес» и «подлинную культуру», порождая вопрос о том, насколько в глобализированном мире сохранилось как культура то, что принято считать таковой даже в «индустриальном» понимании [9].

Указанные процессы в культурной динамике российского общества и мира в целом можно интерпретировать с различных методологических позиций, давая им различные оценки, но мы полагаем, что так или иначе они укладываются в проблемный и теоретический контекст культурного иммунитета общества, о котором на уровне научной рефлексии до сих пор нет ответов на многие воп- 
росы, в том числе и относительно самого понятия «культурный иммунитет». Более разработанным в этом плане является понятие социального иммунитета, в социологической традиции органической теории представляющее «способность общества противостоять социальным рискам и угрозам, прежде всего внешнего характера, связанным с проникновением в общественный организм чужеродных элементов (ценностей, норм, культурных образцов), разрушающих его целостность, интегрированность и адаптационный потенциал» [11, с. 142]. Однако способность общества противостоять рискам и угрозам предполагает наличие иммунной системы, выполняющей роль защитного механизма, отвечающего за устойчивость социокультурного базиса [11], и, следуя логике системного подхода, культурный иммунитет может рассматриваться как важнейший элемент иммунной системы общества, находящийся в системной связи с другими элементами, а потому тонко реагирующий на все изменения, протекающие в социальной системе, в ее институциональном пространстве.

Это пространство детерминировано исторической траекторией общества, что также находит отражение в органической теории, признающей обусловленность настоящего прошлым общества в динамике его развития [18], и позволяет говорить об уникальности не только культуры каждого общества, но его культурного иммунитета. Соответственно, его изучение предполагает обращение к целому комплексу дисциплинарных практик, сложившихся в пространстве социально-гуманитарного знания и раскрывающих особенности институциональной организации социума в современной и исторической динамике; традиции и инновации в культурном развитии общества в его этнокультурном многообразии; региональные факторы социокультурной динамики и многое другое, что требует обращения к теоретическому и прикладному потенциалу целого ряда отраслей научного знания.

Заключение. На уровне социально-философской рефлексии такой подход позволит сформировать трансдисциплинарное методологическое поле исследования культурного иммунитета. Преимуществом такого (трансдисциплинарного) подхода выступает возможность преодоления фрагментированности знания как сопутствующей отдельным дисциплинарным практикам, ограниченным собственными, порой достаточно жесткими, методологическими рамками, в результате чего «ускользает целостность изучаемых социальных явлений» [21].

Таким образом, тематика культурного иммунитета российского общества в оптике научного дискурса представлена в основном как ограниченная дисциплинарными практиками (социологическими, культурологическими, философскими, педагогическими), частично социально-философскими, но последние еще нуждаются в глубокой концептуальной и методологической обеспеченности, и трансдисциплинарная парадигма представляется наиболее адекватной такой задаче, как холистское изучение культурного иммунитета общества.

\section{Литература}

1. Аксенова О.В., Халий И.А. Современное развитие. К постановке темы исследования // Вестник Института социологии. 2018. — №24. - С. 13-26.

2. Арцишшевский A. Что значит для нас культурный иммунитет? [Электронный ресурс]. - Режим доступа: https://camonitor. kz/17460-chto-znachit-dlya-nas-kulturnyyimmunitet.html.

3. Ахиезер А.С. Архаизация в российском обществе как методологическая проблема // Общественные науки и современность. 2001. - №2. - C. 89-100.

4. Бабинцев В.П., Гайдукова Г.Н., Шаповал Ж. А. Феномен социокультурного городского мусора: к постановке проблемы // Урбанистика. - 2020. - №1. - С. 122-133.

5. Баблоян Н.В., Василенко М.А. Социальный иммунитет и пути преодоления социального неравенства [Электронный ресурс]// Инженерный вестник Дона. - 2018. №2. - Режим доступа: https://ivdon.ru/ru/ magazine/archive/n2y2018/4875.

6. В нашем обществе не хватает доверия. Тема с академиком РАН Юрием Бузиашвили [Электронный ресурс]. - Режим доступа: https://rg.ru/2020/04/12/iurij-buziashvili-vnashem-obshchestve-ne-hvataet-doveriia.html. 
7. Дегуманизация культуры в контексте культурологической глобалистики [Электронный ресурс] // Credo New. - 2008. №4. - Режим доступа: http://www.intelros. ru/readroom/credo_new/credo_04_2008/3047degumanizacija-kultury-v-kontekste.html.

8. Джолдошбекова 3.А. Влияние глобализации на национальную культуру и национальное самосознание // Научное обозрение. Педагогические науки. - 2017. - №2. C. 39-43.

9. Евстафьев Д., Цыганова Л. Трансформации социального пространства как предчувствие нового мира [Электронный pecypc]. - Режим доступа: https://expert. $\mathrm{ru} / 2020 / 05 / 6 /$ trans formatsii-sotsialnogoprostranstva-kak-predchuvstvie-novogo-mira/.

10. Жапуев 3.A. Институциональная трансформация как важный фактор влияния на социальный иммунитет: теоретический анализ рисков и угроз [Электронный ресурс]// Гуманитарные, социально-экономические и общественные науки. — 2013. — №1. Режим доступа: https://www.online-science. $\mathrm{ru} / \mathrm{m} /$ products/social_sciense/gid295/pg0/.

11. Жапуев 3.. . Методология исследования социального иммунитета российского общества в условиях институциональной трансформации и рискогенности // Историческая и социально-образовательная мысль. - 2013. - №2. - С. 142-146.

12. Жапуев 3. А. Социальный иммунитет как предмет социологического исследования: концептуализация понятия // Гуманитарные, социально-экономические и общественные науки. - 2013. - №2. - С. 46-50.

13. Захаров В.К. Историческая инерционность самосознания и самоустроения общества // Большая Евразия: Развитие, безопасность, сотрудничество. - 2018. - №1-2. C. 615-617.

14. Ильин В.И. Структура исторической колеи России: проблемы методологии // Мир России. Социология. Этнология. - 2017. №4. - С. 30-50.

15. Кара-Мурза С. Разрушение культуры [Электронный ресурс]. - Режим доступа: http://rossiyanavsegda.ru/read/513/.

16. Колин К. К. Глобализация и культура [Электронный ресурс]. - Режим доступа: http://sec.chgik.ru/globalizatsiya-obshhestva-iee-kulturologicheskie-posledstviya/.
17. Кузьмина Г.П. Органическая концепция развития общества в работах российских социологов-органиков // Соловьевские исследования. - 2010. - С. 36-51.

18. Кузьмина Г.П. Теоретические основы социальной философии П.Ф. Лилиенфельда [Электронный ресурс] // Философия и общество. - 1997. - №4. - Режим доступа: https://www.socionauki.ru/journal/ articles/1458761/.

19. Куц B.A. Защитные функции культуры [Электронный ресурс] // Культура культуры. - 2015. - №2. - Режим доступа: http:// cult-cult.ru/protective-functions-of-culture/.

20. Куи B.A. Культурный иммунитет как передовая линия информационной самозащиты русской культуры и интеллекта россиян // Общество. Среда. Развитие (Terra Humana). - 2013. - №4 (29). - C. 159-164.

21. Лубский А. В. Трансдисциплинарные исследования: проблемы современного эпистемологического дискурса // Гуманитарные, социально-экономические и общественные науки. - 2016. - №12. - С. 61-66.

22. Мельникова А.А., Куц В.А. Глубинные основания русской культуры как база ее иммунитета // Ярославский педагогический вестник. - 2013. - №3. - Т. I (Гуманитарные науки). - С. 220-224.

23. Морозов А.В. Формирование социального иммунитета подростков в условиях среднего профессионального образования как системообразующий фактор безопасного поведения [Электронный ресурс]. - Режим доступа: http://aneks.spb.ru/index.php? catid $=56 \&$ id $=999 \&$ Itemid $=25 \&$ option $=$ com content\&view $=$ article.

24. Мустафаев Ф.М. Факторы разрушения культуры межнационального общения в современном полиэтничном пространстве российского общества // Гуманитарные и социальные науки. - 2014. - №3. - С. 113-123.

25. Норт Д. Институты, институциональные изменения и функционирование экономики / Пер. с англ. А.Н. Нестеренко; предисл. и науч. ред. Б. З. Мильнера. - М.: Фонд экономической книги «Начала», 1997. — 180 с.

26. Ополев П. В. Культурные угрозы в условиях глобализации [Электронный ресурс]. - Грамота, 2016. — №4 (66): в 2-х ч. - Ч. 2. - С. 124-127. - Режим доступа: www.gramota.net/materials/3/2016/4-2/. 
27. Сорокина Н.Д. Конфликты в современной России: причины и методы решения [Электронный ресурс]. — Режим доступа: http://conflictmanagement.ru/konfliktyiv-sovremennoy-rossii-prichinyi-i-metodyiresheniya/.

28. Тер-Геворкова Н.К. Социальное здоровье современной молодежи российского общества // Молодой ученый. - 2019. №12 (250). - С. 237-241.

29. Тихомирова Л. Что такое иммунитет и как его открыли? [Электронный ресурс]. Режим доступа: https://ladadoctor.com/chtotakoe-immunitet-i-kak-ego-otkryli/.

30. Флиер А. Я. Культурная изменчивость и прогресс [Электронный ресурс] // Культура культуры. — 2020. — №3. - Режим доступа: http://www.cult-cult.ru/cultural-variability-andprogress/.

31. Флиер А.Я. Теория культуры: опыт генерализации [Электронный ресурс] // Культура культуры. - 2017. — №4. - Режим доступа: http://cult-cult.ru/the-theory-of-culture-anew-generalization/.

32. Храмичова Ф. И., Ерофеева М.А., Горохова И.В. Духовно-демографическая детерминанта формирования социального иммунитета молодежи в сфере высшего образования [Электронный ресурс]. - Peжим доступа: https://cyberleninka.ru/article/n/ duhovno-demograficheskaya-determinantaformirovaniya-sotsialnogo-immunitetamolodezhi-v-sfere-vysshego-obrazovaniya.pdf.

33. Vereshchagina A.V., Volkov Yu. G., Lyuev A. K., Rachipa A. V., Uzunov V.V. Management of Consolidation Potential of Patriotism in the Regional Space of the South of Russia // International Journal of Applied Exercise Physiology. — 2019. — Vol. 8. — №3. Pp. 400-406.

\section{References}

1. Aksenova O.V., Halij I.A. Sovremennoe razvitie. K postanovke temy issledovanija [Modern development. To the statement of the research topic] // Vestnik Instituta sociologii [Bulletin of the Institute of Sociology]. — 2018. — №24. Pp. 13-26.

2. Arcishevskij A. Chto znachit dlja nas kul'turnyj immunitet? [What does cultural immunity mean for us?] [Jelektronnyj resurs]. -
URL: https://camonitor.kz/17460-chto-znachitdlya-nas-kulturnyy-immunitet.html.

3. Ahiezer A.S. Arhaizacija v rossijskom obshhestve kak metodologicheskaja problema [Archaization in Russian society as a methodological problem] // Obshhestvennye nauki i sovremennost' [Social Sciences and Modernity]. 2001. 一 №2. - Pp. 89-100.

4. Babincev V.P., Gajdukova G.N., Shapoval $\mathrm{Zh}$. A. Fenomen sociokul'turnogo gorodskogo musora: $\mathrm{k}$ postanovke problemy [The phenomenon of socio-cultural urban garbage: to the formulation of the problem] // Urbanistika. 2020. - №1. - Pp. 122-133.

5. Bablojan N.V., Vasilenko M.A. Social'nyj immunitet i puti preodolenija social'nogo neravenstva [Social immunity and ways to overcome social inequality] [Jelektronnyj resurs] // Inzhenernyj vestnik Dona [Engineering Bulletin of the Don]. - 2018. — №2. — URL: https:// ivdon.ru/ru/magazine/archive/n2y2018/4875.

6. V nashem obshhestve ne hvataet doverija. Tema s akademikom RAN Juriem Buziashvili [There is a lack of trust in our society. Topic with Academician of the Russian Academy of Sciences Yuri Buziashvili] [Jelektronnyj resurs]. URL: https://rg.ru/2020/04/12/iurij-buziashvili-v-nashem-obshchestve-ne-hvataet-doveriia. html.

7. Degumanizacija kul'tury $\mathrm{v}$ kontekste kul'turologicheskoj globalistiki [Dehumanization of culture in the context of cultural globalistics] [Jelektronnyj resurs] // Credo New. 2008. — №4. — URL: http://www.intelros.ru/ readroom/credo_new/credo_04_2008/3047degumanizacija-kultury-v-kontekste.html.

8. Dzholdoshbekova Z.A. Vlijanie globalizacii na nacional'nuju kul'turu i nacional'noe samosoznanie [The influence of globalization on national culture and national self-consciousness]// Nauchnoe obozrenie. Pedagogicheskie nauki [Scientific review. Pedagogical sciences]. 一 2017. — №2. — Pp. 39-43.

9. Evstaf'ev D., Cyganova L. Transformacii social'nogo prostranstva kak predchuvstvie novogo mira [Transformations of social space as a premonition of the new world] [Jelektronnyj resurs]. — URL: https://expert.ru/2020/05/6/ transformatsii-sotsialnogo-prostranstva-kakpredchuvstvie-novogo-mira/.

10. Zhapuev Z. A. Institucional'naja transformacija kak vazhnyj faktor vlijanija na social'nyj 
immunitet: teoreticheskij analiz riskov i ugroz [Institutional transformation as an important factor of influence on social immunity: theoretical analysis of risks and threats] [Jelektronnyj resurs]// Gumanitarnye, social'no-jekonomicheskie i obshhestvennye nauki [Humanities, socio-economic and social sciences]. — 2013. №1. — URL: https://www.online-science.ru/m/ products/social_sciense/gid295/pg0/.

11. Zhapuev Z.A. Metodologija issledovanija social'nogo immuniteta rossijskogo obshhestva $\mathrm{v}$ uslovijah institucional'noj transformacii i riskogennosti [Methodology of research of social immunity of the Russian society in the conditions of institutional transformation and riskogeneity] // Istoricheskaja i social'noobrazovatel'naja mysl' [Historical and socioeducational thought]. - 2013. - №2. Pp. 142-146.

12. Zhapuev Z.A. Social'nyj immunitet kak predmet sociologicheskogo issledovanija: konceptualizacija ponjatija [Social immunity as a subject of sociological research: conceptualization of the concept] // Gumanitarnye, social'nojekonomicheskie i obshhestvennye nauki $[\mathrm{Hu}-$ manities, socio-economic and social sciences]. - 2013. - №2. - Pp. 46-50.

13. Zaharov V.K. Istoricheskaja inercionnost' samosoznanija i samoustroenija obshhestva [Historical inertia of self-consciousness and self-organization of society] // Bol'shaja Evrazija: Razvitie, bezopasnost', sotrudnichestvo [Greater Eurasia: Development, security, cooperation]. - 2018. — №1-2. — Pp. 615-617.

14. Il'in V.I. Struktura istoricheskoj kolei Rossii: problemy metodologii [The structure of the historical track of Russia: problems of methodology] // Mir Rossii. Sociologija. Jetnologija [The world of Russia. Sociology. Ethnology]. 2017. — №4. - Pp. 30-50.

15. Kara-Murza S. Razrushenie kul'tury [Destruction of culture] [Jelektronnyj resurs]. URL: http://rossiyanavsegda.ru/read/513/.

16. Kolin K. K. Globalizacija i kul'tura [Globalization and culture] [Jelektronnyj resurs]. URL: http://sec.chgik.ru/globalizatsiya-obshhestva-i-ee-kulturologicheskie-posledstviya/.

17. Kuz'mina G.P. Organicheskaja koncepcija razvitija obshhestva $v$ rabotah rossijskih sociologov-organikov [The organic concept of the development of society in the works of Russian sociologists-organics] // Solov'evskie issle- dovanija [Sociological research]. — 2010. Pp. 36-51.

18. Kuz'mina G.P. Teoreticheskie osnovy social'noj filosofii P.F. Lilienfel'da [Theoretical foundations of social philosophy of P.F. Lilienfeld] [Jelektronnyj resurs] // Filosofija i obshhestvo [Philosophy and Society]. — 1997. №4. — URL: https://www.socionauki.ru/journal/articles/1458761/.

19. Kuc V.A. Zashhitnye funkcii kul'tury [Protective functions of culture] [Jelektronnyj resurs] // Kul'tura kul'tury. — 2015. - №2. URL: http://cult-cult.ru/protective-functions-ofculture/.

20. Kuc V.A. Kul'turnyj immunitet kak peredovaja linija informacionnoj samozashhity russkoj kul'tury i intellekta rossijan [Russian culture immunity as a front line of information self-defense of Russian culture and intelligence of Russians] // Obshhestvo. Sreda. Razvitie (Terra Humana). — 2013. — №4 (29). Pp. 159-164.

21. Lubskij A.V. Transdisciplinarnye issledovanija: problemy sovremennogo jepistemologicheskogo diskursa [Transdisciplinary research: problems of modern epistemological discourse] // Gumanitarnye, social'no-jekonomicheskie i obshhestvennye nauki [Humanities, Socio-economic and Social Sciences]. 2016. 一 №12. — Pp. 61-66.

22. Mel'nikova A. A., Kuc V.A. Glubinnye osnovanija russkoj kul'tury kak baza ee immuniteta [Deep foundations of Russian culture as the basis of its immunity] // Jaroslavskij pedagogicheskij vestnik [Yaroslavl Pedagogical Bulletin]. - 2013. - №3. - Vol. I (Gumanitarnye nauki). - Pp. 220-224.

23. Morozov A. $V$. Formirovanie social'nogo immuniteta podrostkov $\mathrm{v}$ uslovijah srednego professional'nogo obrazovanija kak sistemoobrazujushhij faktor bezopasnogo povedenija [Formation of social immunity of adolescents in the conditions of secondary vocational education as a system-forming factor of safe behavior] [Jelektronnyj resurs]. — URL: http://aneks.spb. $\mathrm{ru} /$ index.php? catid $=56 \& \mathrm{id}=999 \&$ Itemid $=25 \&$ o ption $=$ com content $\&$ view $=$ article.

24. Mustafaev F.M. Faktory razrushenija kul'tury mezhnacional'nogo obshhenija v sovremennom polijetnichnom prostranstve rossijskogo obshhestva [Factors of destruction of the culture of interethnic communication in the modern mul- 
ti-ethnic space of the Russian society] // Gumanitarnye i social'nye nauki [Humanities and Social Sciences]. - 2014. - №3. - Pp. 113-123.

25. Nort $D$. Instituty, institucional'nye izmenenija i funkcionirovanie jekonomiki [Institutes, institutional changes and functioning of the economy] / Per. s angl. A. N. Nesterenko; in B.Z. Mil'ner (eds). - Moscow: Fond jekonomicheskoj knigi «Nachala», 1997. — 180 p.

26. Opolev P. V. Kul'turnye ugrozy v uslovijah globalizacii [Cultural threats in the context of globalization] [Jelektronnyj resurs]. - Gramota, 2016. - №4 (66): in 2 parts. - Part 2. Pp. 124-127. — URL: www.gramota.net/materials/3/2016/4-2/.

27. Sorokina N.D. Konflikty v sovremennoj Rossii: prichiny i metody reshenija [Conflicts in modern Russia: causes and methods of solution] [Jelektronnyj resurs]. — URL: http://conflictmanagement.ru/konfliktyi-v-sovremennoy-rossii-prichinyi-i-metodyi-resheniya/.

28. Ter-Gevorkova N.K. Social'noe zdorov'e sovremennoj molodezhi rossijskogo obshhestva [Social health of modern youth of the Russian society] // Molodoj uchenyj [Young scientist]. 2019. — №12 (250). — Pp. 237-241.

29. Tihomirova L. Chto takoe immunitet i kak ego otkryli? [What is immunity and how was it discovered?] [Jelektronnyj resurs]. — URL: https://ladadoctor.com/chto-takoe-immunitet-ikak-ego-otkryli/.

30. Flier A. Ja. Kul'turnaja izmenchivost' i progress [Cultural variability and progress] [Jelektronnyj resurs] // Kul'tura kul'tury. 2020. — №3. - URL: http://www.cult-cult.ru/ cultural-variability-and-progress/.

31. Flier A. Ja. Teorija kul'tury: opyt generalizacii [The theory of culture: the experience of generalization] [Jelektronnyj resurs] // Kul'tura kul'tury. - 2017. — №4. - URL: http://cult-cult. $\mathrm{ru} /$ the-theory-of-culture-a-new-generalization/.

32. Hramcova F.I., Erofeeva M.A., GorohovaI.V. Duhovno-demograficheskaja determinanta formirovanija social'nogo immuniteta molodezhi v sfere vysshego obrazovanija [Spiritual and demographic determinant of the formation of social immunity of youth in the field of higher education] [Jelektronnyj resurs]. URL: https://cyberleninka.ru/article/n/duhovnodemograficheskaya-determinanta-formirovaniyasotsialnogo-immuniteta-molodezhi-v-sferevysshego-obrazovaniya.pdf.

33. Vereshchagina A. V., Volkov Yu. G., Lyuev A.K., Rachipa A.V., Uzunov V.V. Management of Consolidation Potential of Patriotism in the Regional Space of the South of Russia // International Journal of Applied Exercise Physiology. - 2019. - Vol. 8. - №3. - Pp. 400-406.

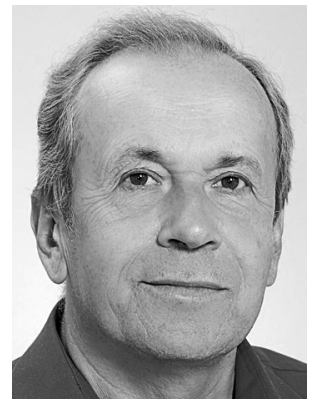

Пономарев Петр Андреевич - доктор философских наук, ведущий научный сотрудник Донского государственного технического университета.

Ponomarev Pyotr Andreevich - Doctor of Philosophical Sciences, Leading Researcher, Don State Technical University.

346916, г. Новошахтинск, ул. Куйбышева, 20

20 Kuibysheva st., 346916, Novoshakhtinsk, Russia

E-mail: ponomarev_p@mail.ru 


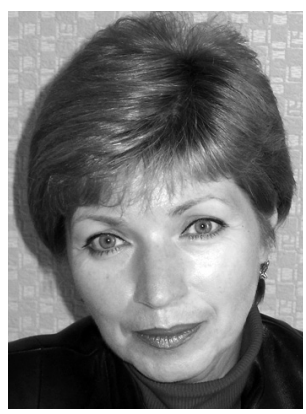

Тищенко Ирина Александровна - доцент, кандидат педагогических наук, доцент кафедры «Экономика и управление» Шахтинского автодорожного института (филиала) Южно-Российского государственного политехнического университета (НПИ) имени М.И. Платова.

Tishchenko Irina Aleksandrovna - Associate Professor, Candidate of Pedagogical Sciences, Associate Professor of «Economics and Management» Department, Shakhty Road Institute (branch), Platov South Russian State Polytechnic University (NPI).

346500, г. Шахты, пл. Ленина, 1

1 Lenina sq., 346500, Shakhty, Russia

E-mail: lingvan@yandex.ru

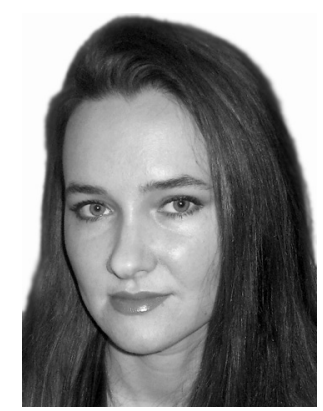

Якунина Инна Сергеевна - кандидат социологических наук, доцент кафедры «Экономика и управление» Шахтинского автодорожного института (филиала) Южно-Российского государственного политехнического университета (НПИ) имени М.И. Платова.

Yakunina Inna Sergeevna - Candidate of Sociological Sciences, Associate Professor of «Economics and Management» Department, Shakhty Road Institute (branch), Platov South Russian State Polytechnic University (NPI).

346500, г. Шахты, пл. Ленина, 1

1 Lenina sq., 346500, Shakhty, Russia

E-mail: babushka30@yandex.ru 